\title{
$P D-1$ gene promoter polymorphisms correlate with a poor prognosis in non-small cell lung cancer
}

\author{
HIDEFUMI SASAKI, TSUTOMU TATEMAYSU, KATSUHIRO OKUDA, \\ SATORU MORIYAMA, MOTOKI YANO and YOSHITAKA FUJII
}

\begin{abstract}
Department of Oncology, Immunology and Surgery, Nagoya City University Graduate School of Medical Sciences, Nagoya, Aichi 467-8601, Japan
\end{abstract}

Received March 27, 2014; Accepted June 21, 2014

DOI: $10.3892 / \operatorname{mco} .2014 .358$

\begin{abstract}
An imbalance to the regulation of the immune system changes the tumor-specific T-cell immunity in the cancer microenvironment and adjusts the tumor progression and metastasis. Inhibiting the interactions of the immune function mediates the antitumor activity in preclinical models. The programmed death 1 ( $P D-1)$ gene -606 G/A polymorphism, which may modify promoter activity and is Asian-specific, was investigated by TaqMan quantitative polymerase chain reaction assay in surgically treated non-small cell lung cancer (NSCLC) cases. In the present study, 583 surgically removed NSCLC cases were included for single-nucleotide polymorphism (SNP) analyses. The $P D-1$ SNP statuses at the promoter region (rs36084323) were 146 AA (25.0\%), 293 GA (50.3\%) and $144 \mathrm{GG}(24.7 \%)$. The ratio was extremely similar to the healthy control in a previous study: $24.9 \%$ AA, $47.8 \%$ GA and $27.3 \%$ GG. The ratio of the GG phenotype was not significantly different for gender (25.1\% males and $23.9 \%$ female), age $(25.2 \% \leq 65$ years and $24.4 \%>65$ years), smoking status $(26.1 \%$ smoker and $21.8 \%$ non-smoker) and pathological subtypes [25.4\% adenocarcinoma (adeno) and 24.2\% squamous cell carcinoma (SCC)]. The GG ratio of $P D-1$ was not significantly different between pathological stage II-IV (25.5\%) and stage I cases $(24.1 \% ; \mathrm{P}=0.6245)$. The survival time of the patients with the $-606 \mathrm{GG}$ phenotype of $P D-1$ was significantly lower ( $\mathrm{n}=147,50$ succumbed) compared to the patients with -606 GA or -606 AA $(n=435,109$ succumbed $)(P=0.0183)$. The GG phenotype patients had a significantly worse prognosis in the SCC population $(\mathrm{P}=0.009)$, however, this was not different to the adeno population $(\mathrm{P}=0.2594)$. Thus, $P D-1$ may promote
\end{abstract}

Correspondence to: Dr Hidefumi Sasaki, Department of Oncology, Immunology and Surgery, Nagoya City University Graduate School of Medical Sciences, 1 Kawasumi, Mizuho-cho, Mizuho-ku, Nagoya, Aichi 467-8601, Japan

E-mail: hisasaki@med.nagoya-cu.ac.jp; hisasaki@hotmail.com

Key words: programmed death 1, immunotherapy, lung cancer, prognosis, squamous cell carcinomas tumor prognosis and provide a candidate for the blockade of its function as a strategy to antagonize the progression process in NSCLC, particularly lung SCC.

\section{Introduction}

Lung cancer, which is usually diagnosed at an advanced stage, is a major cause of mortality from malignant diseases due to its high incidence, malignant behavior and lack of major advancements in treatment strategy (1). Lung cancer was the leading cause for respiratory surgery (48.9\%) in 2011 in Japan (2) and >33,000 patients underwent surgery for lung cancer at Japanese institutions in the same year (2). The clinical behavior of non-small cell lung cancer (NSCLC) is largely associated with its stage, and surgery can only cure the early stage NSCLC disease (3). Chemotherapy is the therapeutic mainstay for squamous NSCLC, however, recent advances in target therapy for NSCLC have increased the treatment choices for non-squamous NSCLC. One novel promising therapeutic approach may be immunotherapy (4).

Circulating immune cells may be able to identify, infiltrate and eliminate certain incipient cancer cells, however, some may bypass the immune surveillance and immune system-mediated cell death (5). Recent studies have enhanced the understanding of the molecular basis for this phenomenon and have facilitated in the identification of anticancer approaches that act by modulating the immune system. An imbalance of the immune system regulation changes the tumor-specific T-cell immunity in the cancer microenvironment and adjusts the tumor progression and metastasis (6). Limited immunostimulatory activation can be detrimental if it impedes the immune responses against cancer (7). Numerous receptor-ligand interactions are known to trigger anti-apoptotic pathways that prevent the activation-induced T-cell death $(8,9)$. The programmed death 1 (PD-1) protein, a T-cell co-inhibitory receptor, plays a central role in the ability of the tumor cells to escape the host immune system. PD-L1, one of the ligands, is selectively expressed in a number of tumors (10-12). Inhibition of the interactions between PD-1 and PD-L1 improves the immune function in vitro and mediates antitumor activity in preclinical models $(10,11)$. Recent studies have indicated that the antibody-mediated blockade of PD-1 (13) and PD-L1 (14) induced durable tumor regression 
and prolonged stabilization of disease in certain patients with advanced cancers, including NSCLC. The PD-1 -606 G allele at the promoter showed a significant correlation with Japanese subacute sclerosing panencephalitis (SSPE) (15). This -606 G/A single-nucleotide polymorphism (SNP) resides in the putative binding site for UCE-2 transcription regulators (GGCCG at position -610 to -606). A haplotype of the $-606 \mathrm{G}$ allele with a high promoter activity was correlated with the development of SSPE (15). The relative PD-1 expression was higher in SSPE patients compared to the control (15), however, the correlation between this Asian-specific PD-1 SNP and NSCLC has not been well investigated.

In the present study, the $P D-1$ and cytotoxic T-lymphocyte-associated antigen $4(C T L A-4)$ gene polymorphisms were investigated in Japanese patients with NSCLC using TaqMan genotyping quantitative polymerase chain reaction (qPCR) in surgically-treated cases. The findings were compared to the clinicopathological features of NSCLC and the $P D-1$ or $C T L A-4$ gene SNP statuses.

\section{Patients and methods}

Patient samples. The study group included NSCLC patients who had undergone surgery at the Department of Surgery, Nagoya City University Hospital (Nagoya, Japan) between 1997 and 2012. All the tumor samples were immediately frozen and stored at $-80^{\circ} \mathrm{C}$ until analysis. The patient consent was obtained from all the patients. The study was approved by the Ethics Committee of the University. The clinical and pathological characteristics of the 583 NSCLC patients for $P D-1$ gene analyses were as follows: 399 males (68.4\%), 184 females (31.6\%), 366 diagnosed with adenocarcinomas (adeno) (62.8\%) and 161 with squamous cell carcinomas (SCC) $(27.6 \%)$, 395 smokers (67.8\%), 188 non-smokers (32.2\%) and 348 with pathological stage I (59.7\%).

qPCR assay for the PD-1 gene. Genomic DNA was extracted from peripheral blood or thymus tissues using Wizard SV Genomic DNA Purification system (Promega, Madison, WI, USA) according to the manufacturer's instructions. The DNA concentration was determined by a NanoDrop ND-1000 spectrophotometer (NanoDrop Technologies, Inc., Rockland, DE, USA). The primers and TaqMan probes for $P D-1$ (-606 G/A, codon -606 of promoter, rs36084323; +6371 G/A, intron 2, rs34819629) and CTLA-4 (+49A/G, codon 17 of exon 1 , rs231775) were designed at Applied Biosystems (Foster City, CA, USA). For the SNP genotyping, one pair of TaqMan probes and one pair of PCR primers were used. The two TaqMan probes differed at the polymorphic site, with one probe complementary to the wild-type and the other complementary to the variant allele. TaqMan PCR and genotyping analysis were performed on an Applied Biosystems 7500 Real-Time PCR system. The reaction mixture were amplified in $1 \mu \mathrm{l}$ template DNA (10 ng/ $\mu \mathrm{l}), 12.5 \mu \mathrm{l} 2 \mathrm{X}$ TaqMan Universal Master mix, $0.625 \mu 120 \mathrm{X}$ primer/probe mix and $10.875 \mu \mathrm{l}$ $\mathrm{ddH}_{2} \mathrm{O}$ in a total volume of $25 \mu \mathrm{l}$. The cycling conditions were as follows: Initial denaturation at $95^{\circ} \mathrm{C}$ for $10 \mathrm{~min}$, followed by 40 cycles at $95^{\circ} \mathrm{C}$ for $15 \mathrm{sec}$ and $58^{\circ} \mathrm{C}$ for $1 \mathrm{~min}$. The results were analyzed on the Applied Biosystems 7500 Real-Time PCR system using the alleic discrimination assay program.
Immunohistochemistry. The specimens were cut into $4-\mu \mathrm{m}$ sections and were deparaffinized by xylene and alcohol. Endogenous peroxidase activity was blocked by the peroxidase blocking reagent (R\&D Systems, Minneapolis, MN, USA) for 5 min. Subsequently, the sections were washed three times in phosphate-buffered saline (PBS). The nonspecific binding was blocked with serum-blocking reagent D (Cell Tissue Staining kit, no. 008) for $15 \mathrm{~min}$ and the sections were incubated with avidin-blocking reagent for $15 \mathrm{~min}$ and biotin-blocking reagent for $15 \mathrm{~min}$. The sections were incubated with the primary anti-PD-1 antibody (R\&D Systems) in a humid chamber at $4^{\circ} \mathrm{C}$ overnight. Following three washes with PBS, the sections were incubated with biotinylated secondary antibodies for $45 \mathrm{~min}$, washed three times in PBS and incubated with streptavidin-conjugated peroxidase for $30 \mathrm{~min}$. Subsequent to three additional washes in PBS, 3,3'-diaminobenzidine tetrahydrochloride chromogen buffer was applied and the sections were counterstained with hematoxylin. The sections were determined as positive if $>10 \%$ of the tumor-infiltrating lymphocytes (TILs) were stained (16).

Statistical analysis. Statistical analyses were performed using the Student's t-test for unpaired samples and $\chi^{2}$ test for paired samples. Correlation coefficients were determined using $\chi^{2}$ test. The overall survival time of the lung cancer patients was examined by the Kaplan-Meier methods and the differences were examined by the log-rank test. All the analyses were conducted using the StatView software package (Abacus Concepts, Inc., Berkeley, CA, USA) and $\mathrm{P}<0.05$ was considered to indicate a statistically significant difference.

\section{Results}

PD-1 DNA status in Japanese lung cancer patients. The $P D-1$ gene promoter polymorphism status was genotyped for 583 NSCLC samples. The PD-1 -606 SNP statuses at the promoter region (rs36084323) were 146 AA (25.0\%), 293 GA $(50.3 \%)$ and $144 \mathrm{GG}(24.7 \%)$. The ratios were extremely similar to the healthy control of the Asian population in a previous study: $24.9 \%$ AA, $47.8 \%$ GA and $27.3 \%$ GG. The PD-1 rs36084323 were 87 AA (23.8\%), 186 AG (50.8\%), 93 GG (25.4\%) in adeno; and 48 AA (29.8\%), 74 AG (46.0\%), $39 \mathrm{GG}(24.2 \%)$ in SCC. The ratio of the GG phenotype was not significantly different between adeno vs. others $(\mathrm{P}=0.6057)$ or SCC vs. others $(\mathrm{P}=0.8692)$. The $\mathrm{GG}$ ratio was not correlated with gender (male vs. female, $25.1 \%$ vs. $23.9 \%$; $\mathrm{P}=0.7648$ ), ages ( $\leq 65$ vs. $>65$ years, 25.5 vs. $24.1 \%$; $\mathrm{P}=0.6987$ ), smoking status (smoker vs. non-smoker, 26.1 vs. $21.8 \% ; \mathrm{P}=0.2641$ ) and $E G F R$ mutations status (wild type vs. mutant patients, 24.7 vs. $24.7 \%$; $\mathrm{P}=0.9934)$. The $\mathrm{GG}$ ratio was not correlated with lymph node metastasis (positive vs. negative, 28.1 vs. 23.3\%; $\mathrm{P}=0.2218$ ). The GG ratio of $P D-1-606$ according to the pathological T stages were as follows: $24.6 \%$ pT1, 24.6\% pT2, $25 \%$ pT3 and $25 \%$ pT4. The GG ratio was not significantly different (pT1 vs. pT2-4, $\mathrm{P}=0.9565)$. The $P D-1-606$ were 80 AA (23.0\%), 184 GA (52.9\%), 84 GG (24.1\%) at stage I; 28 AA (29.2\%), 44 GA (45.8\%), 24 GG (25\%) at stage II; and 38 AA $(27.3 \%), 65$ GA $(46.8 \%), 36$ GG $(25.9 \%)$ at stage III-IV. The ratio of the GG phenotype was not significantly different between stage I vs.stages II-IV (P=0.7018) (Table I). 


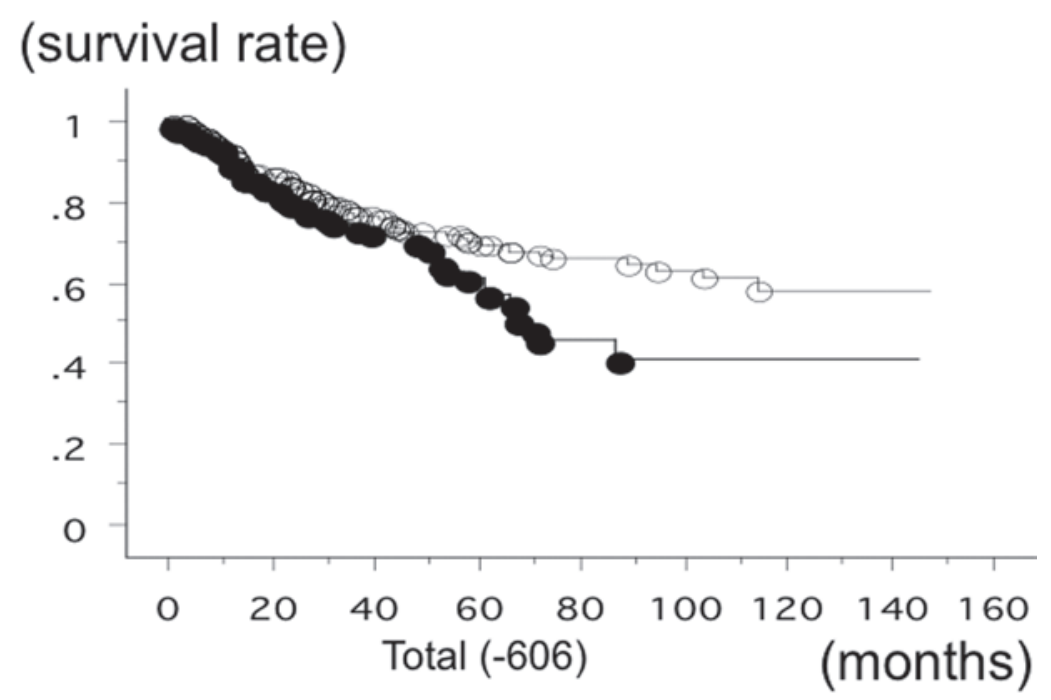

Figure 1. Overall survival time of 583 non-small cell lung cancer patients from Nagoya City University, with a follow-up until August 31, 2013, was studied in reference to the programmed death $1(P D-1)$ gene single-nucleotide polymorphism rs36084323 statuses. The survival time of the patients with -606 GG $P D-1$ $(\bullet ; \mathrm{n}=147,50$ succumbed) was significantly lower compared to the patients with $-606 \mathrm{GA}$ or AA $P D-1$ (O; $\mathrm{n}=436,110$ succumbed) (log-rank test, $\mathrm{P}=0.0183)$.

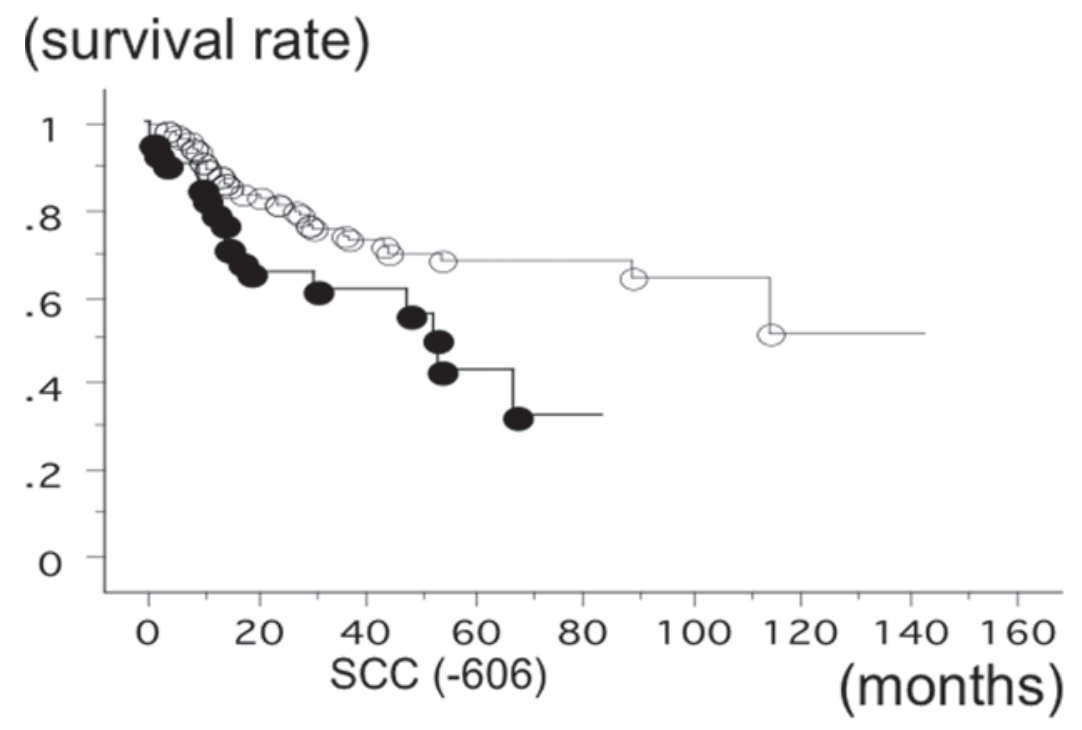

Figure 2. Overall survival time of 166 lung squamous cell carcinoma (SCC) patients from Nagoya City University studied in reference to the programmed death 1 (PD-1) single-nucleotide polymorphism rs36084323 gene statuses. The survival time of the patients with -606 GG $P D-1$ ( $\bullet$; n=42, 18 succumbed) was significantly lower compared to the patients with $-606 \mathrm{GA}$ or AA $P D-1$ (O; $\mathrm{n}=124,33$ succumbed) (log-rank test, $\mathrm{P}=0.0090)$.

The overall survival time of 583 lung cancer patients from Nagoya City University, with a follow-up until August 31, 2013, was studied in reference to the $P D-1$ gene -606 SNP statuses. The survival time of the patients with the -606 GG phenotype of $P D-1$ was significantly lower ( $\mathrm{n}=147 ; 50$ succumbed; mean survival, 60.6 months) compared to the patients with -606 GA or -606 AA ( $n=436 ; 110$ succumbed; mean survival, 84.6 months) (log-rank test, $\mathrm{P}=0.0183$ ) (Fig. 1). The survival rate of the SCC patients with the -606 GG phenotype of $P D-1$ was also significantly lower $(\mathrm{n}=42 ; 18$ succumbed; mean survival, 43.5 months) compared to the patients with -606 GA or -606 AA ( $=124 ; 33$ succumbed; mean survival, 84.3 months) (log-rank test, $\mathrm{P}=0.0090$ ) (Fig. 2). The survival time of the stage I SCC patients with the -606 GG phenotype of PD-1 was significantly worse $(n=19 ; 8$ succumbed; mean survival, 47 months) compared to the patients with $-606 \mathrm{GA}$ or
-606 AA ( $\mathrm{n}=66$; 12 succumbed; mean survival, 95.2 months; $\mathrm{P}=0.0091$ ). However, the survival time of the stage II-IV SCC patients with the $-606 \mathrm{GG}$ and GA or AA was not significantly different $(\mathrm{P}=0.2840)$. The survival time of the adeno patients with the $-606 \mathrm{GG}$ phenotype of $P D-1$ ( $\mathrm{n}=93 ; 28$ succumbed; mean survival, 65.1 months) and with the patients with -606 GA or -606 AA ( $\mathrm{n}=273$; 68 succumbed; mean survival, 79.2 months) was not significantly different $(\mathrm{P}=0.2718)$. Univariate analysis demonstrated that pathological stage (I vs. II-IV, $\mathrm{P}<0.0001$ ), smoking status (non-smoker vs. smoker, $\mathrm{P}=0.007)$ and gender $(\mathrm{P}=0.006)$ were the prognostic factors for NSCLC in the present cohort. Multivariate analysis showed that pathological stage (hazard ratio, 2.751; $\mathrm{P}<0.0001$ ), gender (hazard ratio, 1.795; $\mathrm{P}=0.0204$ ) and $P D-1-606 \mathrm{GG}$ (hazard ratio, 1.431; $\mathrm{P}=0.037$ ) were the independent prognostic factors. Disease-free survival (DFS) was evaluated for 325 NSCLC 
Table I. Clinicopathological data of 583 lung cancer patients.

\begin{tabular}{|c|c|c|c|c|c|c|c|}
\hline \multirow[b]{2}{*}{ Factors } & \multicolumn{3}{|c|}{$P D-1$} & \multirow[b]{2}{*}{ Factors } & \multicolumn{3}{|c|}{$P D-1+6371$ (intron 2) } \\
\hline & $\begin{array}{c}\mathrm{AA}+\mathrm{GA} \\
\text { patients, n (\%) }\end{array}$ & $\begin{array}{c}\text { GG patients, } \\
\text { n }(\%)\end{array}$ & P-value & & $\begin{array}{c}\mathrm{AA}+\mathrm{GA} \\
\text { patients, n }(\%)\end{array}$ & $\begin{array}{c}\text { GG patients, } \\
\text { n }(\%)\end{array}$ & P-value \\
\hline $\begin{array}{l}\text { Mean age } \\
66.7 \pm 9.3 \text { years }\end{array}$ & $439(66.7 \pm 9.4)$ & $144(66.3 \pm 9.5)$ & 0.5726 & $\begin{array}{l}\text { Mean age } \\
66.7 \pm 9.3 \text { years }\end{array}$ & $432(66.8 \pm 9.4)$ & $150(65.9 \pm 9.3)$ & 0.2320 \\
\hline Stage & & & & Stage & & & \\
\hline I & $264(60.1)$ & $84(58.3)$ & II-IV & I & $258(59.7)$ & $89(59.3)$ & II-IV \\
\hline II & $72(16.4)$ & $24(16.7)$ & vs. I & II & $73(16.9)$ & $25(16.7)$ & vs. I \\
\hline III-IV & $103(23.5)$ & $36(25.0)$ & 0.7018 & III-IV & $101(23.4)$ & $36(24.0)$ & 0.9333 \\
\hline Tumor status & & & & Tumor status & & & \\
\hline $\mathrm{pT} 1$ & $181(41.2)$ & $59(41.0)$ & $\mathrm{T} 2-4$ & pT1 & $178(41.2)$ & $61(40.7)$ & $\mathrm{T} 2-4$ \\
\hline pT2 & $174(39.6)$ & $57(39.6)$ & vs. T1 & pT2 & $173(40.0)$ & $58(38.7)$ & vs. T1 \\
\hline pT3 & $51(11.6)$ & $17(11.8)$ & 0.9934 & pT3 & $48(11.1)$ & $20(13.3)$ & 0.9083 \\
\hline pT4 & $33(7.5)$ & $11(7.6)$ & & pT4 & $33(7.6)$ & $11(7.3)$ & \\
\hline $\begin{array}{l}\text { Lymph node } \\
\text { metastasis }\end{array}$ & & & & $\begin{array}{l}\text { Lymph node } \\
\text { metastasis }\end{array}$ & & & \\
\hline Negative & $319(72.7)$ & $97(67.4)$ & 0.2218 & Negative & $310(71.8)$ & $105(70.0)$ & 0.6815 \\
\hline Positive & $120(27.3)$ & $47(32.6)$ & & Positive & $122(28.2)$ & $45(30.0)$ & \\
\hline Age, years & & & & Age, years & & & \\
\hline$\leq 65$ & $184(41.9)$ & $63(43.8)$ & 0.6987 & $\leq 65$ & $175(40.5)$ & $72(48.0)$ & 0.1098 \\
\hline$>65$ & $255(58.1)$ & $81(56.3)$ & & $>65$ & $257(59.5)$ & $78(52.0)$ & \\
\hline$E G F R$ mutation & & & & $E G F R$ mutation & & & \\
\hline Positive & $116(26.4)$ & $38(26.4)$ & 0.9934 & Positive & $116(26.9)$ & $38(25.3)$ & 0.7164 \\
\hline Negative & $323(73.6)$ & $106(73.6)$ & & Negative & $316(73.1)$ & $112(74.7)$ & \\
\hline Smoking & & & & Smoking & & & \\
\hline $\mathrm{BI}=0$ & $147(33.5)$ & $41(28.5)$ & 0.2641 & $\mathrm{BI}=0$ & $146(33.8)$ & $42(28.0)$ & 0.1909 \\
\hline $\mathrm{BI}>0$ & $292(66.5)$ & $103(71.5)$ & & $\mathrm{BI}>0$ & $286(66.2)$ & $108(72.0)$ & \\
\hline $\begin{array}{l}\text { Pathological } \\
\text { subtypes }\end{array}$ & & & & $\begin{array}{l}\text { Pathological } \\
\text { subtypes }\end{array}$ & & & \\
\hline Adeno & $273(62.2)$ & $93(64.6)$ & SCC vs. & Adeno & $269(62.3)$ & 97 (64.7) & SCC vs. \\
\hline Squamous & $122(27.8)$ & $39(27.1)$ & others & Squamous & $118(27.3)$ & $42(28.0)$ & others \\
\hline Others & $44(10.0)$ & $12(8.3)$ & 0.8692 & Others & $45(10.4)$ & $11(7.3)$ & 0.8714 \\
\hline Gender & & & & Gender & & & \\
\hline Male & $299(68.1)$ & $100(69.4)$ & 0.7648 & Male & $291(67.4)$ & 107 (71.3) & 0.3674 \\
\hline Female & $140(31.9)$ & $44(30.6)$ & & Female & $141(32.6)$ & 43 (28.7) & \\
\hline
\end{tabular}

$P D$-1, programmed death 1; EGFR, epidermal growth factor receptor; BI, Brinkman index; Adeno, adenocarcinoma; SCC, squamous cell carcinoma.

cases. The DFS of PD-1 -606 GG (21/80 succumbed; mean survival, 52.6 months) and -606 GA or AA (59/245 succumbed; mean survival, 56.4 months) was not significantly different $(\mathrm{P}=0.7178)$.

PD-L1/ $\beta$-actin mRNA levels in NSCLC were evaluated in our previous study (17). PD-L1/ $\beta$-actin mRNA levels were AA, 5.838 $\pm 8.265(n=34) ; G A, 3.113 \pm 7.317(n=64)$; and GG, 45.791 $\pm 238.663(n=36)$. There was a tendency towards higher PD-L1/ $\beta$-actin mRNA levels in GG compared to $\mathrm{GA}+\mathrm{AA}(4.059 \pm 7.726$; $\mathrm{P}=0.0842)$. The $\mathrm{PD}-1$ protein expression was evaluated by immunohistochemistry. Only one case
Table II. Clinicopathological data of 582 lung cancer patients.

$P D$ - 1, programmed death $1 ; E G F R$, epidermal growth factor receptor; $\mathrm{BI}$, Brinkman index; Adeno, adenocarcinoma; SCC, squamous cell carcinoma.

(GG case) showed extremely high PD-1 signals (Fig. 3). The (47.1\%); and AA, 2/10 (20\%). There was a tendency towards higher PD-1-positive sections in GG compared to GA or AA $(\mathrm{P}=0.0809)$.

The $P D-1+6371$ SNP statuses at the intron 2 region (rs34819629) were 134 AA (23.0\%), 298 GA (51.2\%) and $150 \mathrm{GG}(25.8 \%)$. The ratio was extremely similar to the promoter -606 SNP and $89.7 \%$ was identical. The $P D-1$ rs34819629 were 83 AA (22.7\%), 186 AG (50.8\%), 97 GG (26.5\%) in adeno; and 42 AA (26.3\%), 76 AG (47.5\%), 42 GG PD-1-positive sections (TILs) were GG, 7/21 (66.7\%); GA, 8/9 
$(26.3 \%)$ in SCC. The ratio of the GG phenotype was not significantly different between adeno vs. others $(\mathrm{P}=0.6004)$ or SCC vs. others $(\mathrm{P}=0.8714)$. The $\mathrm{GG}$ ratio was not correlated with gender (male vs. female, 26.9 vs. $23.4 \%$; $\mathrm{P}=0.3674$ ), ages ( $\leq 65$ vs. $>65$ years, 29.2 vs. $23.3 \%$; $\mathrm{P}=0.1098$ ), smoking status (smoker vs. non-smoker, 27.4 vs. $22.8 \%$; $\mathrm{P}=0.1909$ ) and $E G F R$ mutations status (wild type vs. mutant patients, 26.2 vs. $24.7 \%$; $\mathrm{P}=0.7164)$. The $\mathrm{GG}$ ratio was not correlated with lymph node metastasis (positive vs. negative, 26.9 vs. $25.3 \%$; $\mathrm{P}=0.6815$ ). The GG ratio of $P D-1+6371$ according to the pathological T stages were as follows: $25.5 \%$ pT1, 25.1\% pT2, 29.4\% pT3 and $25 \%$ pT4. The GG ratio was not significantly different (pT1 vs. pT2-4; $\mathrm{P}=0.9083$ ). The $P D-1+6371$ were 73 AA (21.0\%), 185 GA (53.3\%), 89 GG (25.6\%) in stage I; 26 AA (26.8\%), $47 \mathrm{GA}(48.5 \%), 24 \mathrm{GG}(24.7 \%)$ at stage II; and $35 \mathrm{AA}$ (25.5\%), 66 GA (48.2\%), 36 GG $(26.3 \%)$ at stages III-IV. The ratio of the GG phenotype was not significantly different between stage I vs.stages II-IV ( $\mathrm{P}=0.9333)$ (Table II).

The overall survival time of 582 lung cancer patients was studied in reference to the $P D-1$ gene +6371 SNP status. The survival time of the patients with the +6371 GG phenotype of $P D-1$ was significantly lower $(n=151 ; 52$ succumbed; mean survival, 52.8 months) compared to the patients with +6371 GA or AA $(n=431 ; 108$ succumbed; mean survival, 84.6 months) (log-rank test, $\mathrm{P}=0.0103$ ) (Fig. 4). The survival time of the SCC patients with the +6371 GG phenotype of $P D-1$ was also significantly worse $(\mathrm{n}=42 ; 19$ succumbed; mean survival, 42.9 months) compared to the patients with +6371 GA or +6371 AA ( $\mathrm{n}=123$; 33 succumbed; mean survival, 84.6 months) (log-rank test, $\mathrm{P}=0.0063$ ). However, the survival time of the adeno patients with the +6371 GG phenotype of $P D-1$ (n=98; 30 succumbed; mean survival, 56.3 months) and with the patients with +6371 GA or AA ( $n=268 ; 66$ succumbed; mean survival, 79.6 months) was not significantly different $(\mathrm{P}=0.1492)$. Multivariate analysis showed pathological stage (hazard ratio, 2.775; $\mathrm{P}<0.0001$ ), gender (hazard ratio, 1.779; $\mathrm{P}=0.0224$ ) and $P D-1+6371 \mathrm{GG}$ (hazard ratio, $1.516 ; \mathrm{P}=0.0141$ ) were the independent prognostic factors.

CTLA-4 +49 SNP status in Japanese lung cancer patients. The CTLA-4 +49 SNP statuses at exon 1 (rs231775) were 86 AA (14.8\%), 284 GA (48.7\%) and 213 GG (36.5\%). The ratio was extremely similar to the Chinese lung cancer cohort in a previous study: $13.6 \% \mathrm{AA} ; 42.0 \% \mathrm{GA}$ and $44.0 \% \mathrm{GG}$. The CTLA-4 +49 were 55 AA (15.0\%), 184 AG (50.3\%), 127 GG (34.7\%) in adeno; and 22 AA (13.7\%) 80 AG (49.7\%), 59 GG $(36.6 \%)$ in SCC. The ratio of the AA phenotype was not significantly different between adeno vs. others $(\mathrm{P}=0.8072)$ or SCC vs. others $(\mathrm{P}=0.6477)$. The AA ratio was not correlated with gender (male vs. female, 14.8 vs. $14.7 \%$; $\mathrm{P}=0.9715$ ), ages ( $\leq 65$ vs. $>65$ years, 15.4 vs. $14.3 \% ; \mathrm{P}=0.7116$ ), smoking status (smoker vs. non-smoker, 14.2 vs. $16.0 \% ; \mathrm{P}=0.5710$ ) and $E G F R$ mutations status (wild type vs. mutant patients, 14.2 vs. $16.2 \%$; $\mathrm{P}=0.5453)$. The AA ratio had a lower tendency in the patients with lymph node metastasis $(10.8 \%)$ compared to the patients without lymph node metastasis $(16.3 \%)(\mathrm{P}=0.0865)$. The AA ratio of CTLA- $4+49$ according to the pathological T stages were as follows: $14.6 \%$ pT1, $16.4 \%$ pT2, $10.3 \%$ pT3 and $13.6 \%$ pT4. The AA ratio was not significantly different (pT1 vs. pT2-4, $\mathrm{P}=0.9238$ ). The $C T L A-4+49$ were 57 AA

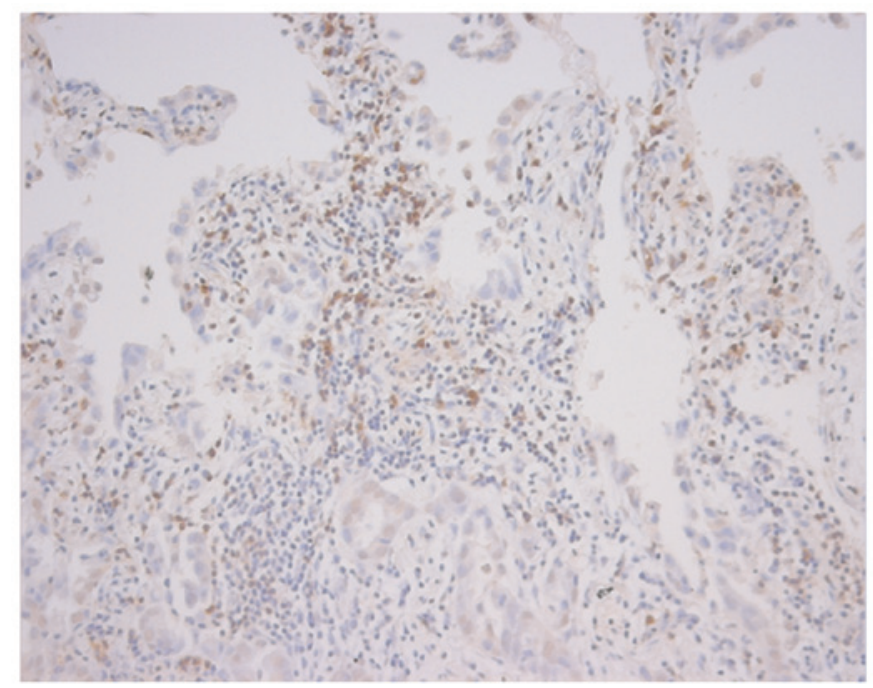

Figure 3. Programmed death 1 expression in tumor-infiltrating lymphocytes by immunohistochemistry.

\section{(survival rate)}

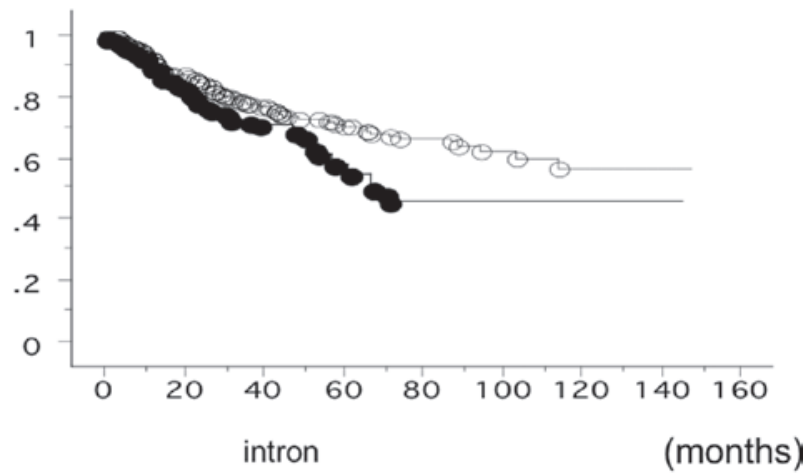

Figure 4. Overall survival time of 582 non-small cell lung cancer (NSCLC) patients from Nagoya City University studied in reference to the programmed death $1(P D-1)$ gene single-nucleotide polymorphism rs34819629 status. The survival time of the patients with +6371 GG PD-1 (•; n=151, 52 succumbed $)$ was significantly lower compared to the patients with +6371 GA or AA $P D-1$ $(\bigcirc ; \mathrm{n}=431,1,108$ succumbed) (log-rank test, $\mathrm{P}=0.0103)$.

\section{(survival rate)}

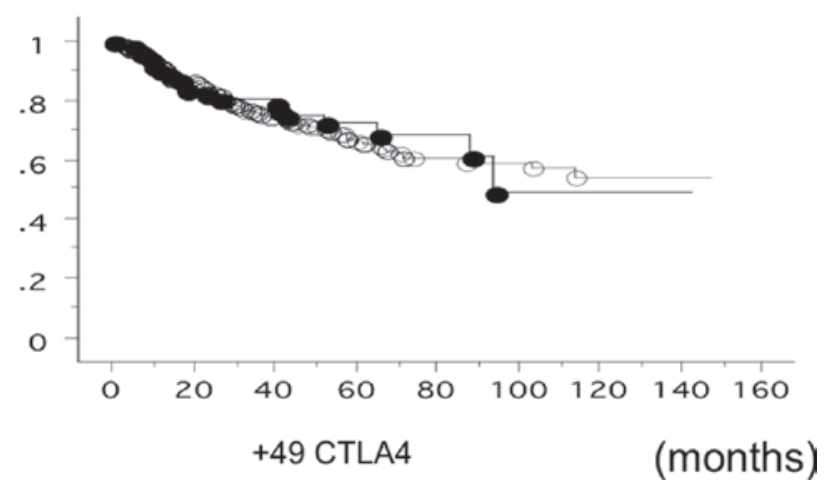

Figure 5. Overall survival time of 583 lung cancer patients from Nagoya City University studied in reference to the cytotoxic T-lymphocyte-associated antigen 4 (CTLA-4) single-nucleotide polymorphism rs231775 gene status. The survival time of the patients with +49 AA $C T L A-4(\bullet ; n=83,21$ succumbed) and the patients with +49 GA or GG CTLA-4 $(\bigcirc ; n=500,140$ succumbed) was not significantly different (log-rank test, $\mathrm{P}=0.6861)$. 
Table III. Clinicopathological data of 583 lung cancer patients.

\begin{tabular}{|c|c|c|c|}
\hline \multirow[b]{2}{*}{ Factors } & \multicolumn{3}{|c|}{ CTLA-4 +49(exon 1$)$} \\
\hline & $\begin{array}{c}\text { AA patients, } \\
\text { n }(\%)\end{array}$ & $\begin{array}{c}\mathrm{AG}+\mathrm{GG} \\
\text { patients, n }(\%)\end{array}$ & $\mathrm{P}$-value \\
\hline $\begin{array}{l}\text { Mean age } \\
66.7 \pm 9.3 \text { years }\end{array}$ & $86(67.9 \pm 9.1)$ & $497(66.3 \pm 9.4)$ & 0.2878 \\
\hline \multicolumn{4}{|l|}{ Stage } \\
\hline I & $57(66.3)$ & $291(58.6)$ & II-IV \\
\hline II & $12(14.0)$ & $86(17.3)$ & vs. I \\
\hline III-IV & $17(19.8)$ & $120(24.1)$ & 0.1774 \\
\hline \multicolumn{4}{|l|}{ Tumor status } \\
\hline $\mathrm{pT} 1$ & $35(40.7)$ & 205 (41.2) & $\mathrm{T} 2-4$ \\
\hline pT2 & $38(44.2)$ & $193(38.8)$ & vs. T1 \\
\hline pT3 & $7(8.1)$ & $61(12.3)$ & 0.3205 \\
\hline pT4 & $6(7.0)$ & $38(7.6)$ & \\
\hline \multicolumn{4}{|l|}{$\begin{array}{l}\text { Lymph node } \\
\text { metastasis }\end{array}$} \\
\hline Negative & $68(79.1)$ & $348(70.0)$ & 0.0865 \\
\hline Positive & $18(20.9)$ & $149(30.0)$ & \\
\hline \multicolumn{4}{|l|}{ Age, years } \\
\hline$\leq 65$ & $38(44.2)$ & $209(42.1)$ & 0.7116 \\
\hline$>65$ & $48(55.8)$ & $288(57.9)$ & \\
\hline \multicolumn{4}{|l|}{$E G F R$ mutation } \\
\hline Positive & $25(29.1)$ & $129(26.0)$ & 0.5453 \\
\hline Negative & $61(70.9)$ & $368(74.0)$ & \\
\hline \multicolumn{4}{|l|}{ Smoking } \\
\hline $\mathrm{BI}=0$ & $30(34.9)$ & $158(31.8)$ & 0.5710 \\
\hline $\mathrm{BI}>0$ & $56(65.1)$ & $339(68.2)$ & \\
\hline \multicolumn{4}{|l|}{$\begin{array}{l}\text { Pathological } \\
\text { subtypes }\end{array}$} \\
\hline Adeno & $55(64.0)$ & $311(62.6)$ & SCC vs. \\
\hline Squamous & $22(25.6)$ & $139(28.0)$ & others \\
\hline Others & $9(10.5)$ & $47(9.5)$ & 0.6477 \\
\hline \multicolumn{4}{|l|}{ Gender } \\
\hline Male & $59(68.6)$ & $340(68.4)$ & 0.9715 \\
\hline Female & $27(31.4)$ & 157 (31.6) & \\
\hline
\end{tabular}

CTLA-4, cytotoxic T-lymphocyte-associated antigen 4; EGFR, epidermal growth factor receptor; BI, Brinkman index; Adeno, adenocarcinoma; SCC, squamous cell carcinoma.

(16.4\%), 160 GA (46.0\%), 131 GG (37.6\%) at stage I; 12 AA (12.2\%), $55 \mathrm{GA}(56.1 \%), 31 \mathrm{GG}(31.6 \%)$ at stage II; and $17 \mathrm{AA}$ (12.4\%), 69 GA (50.4\%), 51 GG (37.2\%) at stage III-IV. The ratio of the AA phenotype was not significantly different between stage I vs. II-IV ( $\mathrm{P}=0.1774)$ (Table III).

The overall survival time of 583 lung cancer was studied in reference to the $C T L A-4$ gene +49 SNP status. The survival of the patients with the AA phenotype of CTLA-4 $(\mathrm{n}=83 ; 21$ 500, 140 succumbed; mean survival, 81.0 months) was not significantly different (log-rank test, $\mathrm{P}=0.6861$ ) (Fig. 5). The survival of the SCC patients with the +49 AA phenotype
( $n=21 ; 9$ succumbed; mean survival, 58.6 months) and the patients with GA or GG ( $\mathrm{n}=146 ; 42$ succumbed; mean survival, 80.3 months) was also not significantly different (log-rank test, $\mathrm{P}=0.2591)$. In addition, the survival time of the adeno patients with the +49 AA phenotype $(n=127 ; 37$ succumbed; mean survival, 54.5 months) and the patients with GA or GG ( $\mathrm{n}=240 ; 39$ succumbed; mean survival, 79.2 months) was not significantly different $(\mathrm{P}=0.2629)$.

\section{Discussion}

The focus of PD-1 in the present study, PD-1 was to investigate whether it may be a novel molecular target for NSCLC. The $P D-1$ gene promoter SNP was found to be correlated with a poor prognosis in surgically-resected NSCLC.

Human cancers retain a number of genetic and epigenetic changes, which can produce neoantigens that are potentially recognizable by the immune system (18). Multistep-resistance systems, including local immuno-suppression, induction of tolerance and systemic dysfunction in T-cell signaling, are initiated by tumors (19-22). Additionally, numerous pathways are utilized by tumors to avoid immune destruction. There are a number of checkpoints in place to modulate this nascent immune response and to avoid the antitumor immune responses. Immune-checkpoint pathways with therapeutic anticancer targeting potential include PD-1, a member of the B7-CD28 family that regulates T-cell activation, peripheral tolerance and the prevention of bystander tissue damage during immune responses, and CTLA-4 pathways, which control the early stages of T-cell activation. Intensive efforts for developing immunotherapeutic approaches for cancer treatment have evolved from these findings, including immune-checkpoint-pathway inhibitors, such as anti-CTLA-4 antibody $(23,24)$ and anti-PD-L1 therapy $(11,12)$. These initial clinical studies using antibodies have shown a promising safety profile and notable antitumor activity in the subsets of patients with metastatic disease.

With regards to tumor immunology, CTLA-4 signaling is more marked in limiting the initiation of a T-cell response in the lymph nodes, whereas the engagement of PD-1 is clearer later in the process and serves to limit the T-cell activity in the tumor microenvironment (25). The +49 adenine-guanine CTLA-4 SNP has been found to increase the risk of cancer (26) and is classified as a prognostic predictor for advanced NSCLC (27). However, in the present study analysis, the CTLA-4 +49 polymorphism did not correlate with the survival rate of surgically-removed NSCLC cases. The discrepancy may be due to the population difference, such as advanced cases. The +49 AA ratio had a lower tendency in the patients with lymph node metastasis. In addition, the presence of the +49 AA allele is small in the Asian population, and therefore, a larger cohort would determine the exact influence of this SNP. By contrast, the role of the $P D-1$ SNP in NSCLC is not well known. PD-1 is a key immune-checkpoint receptor that is expressed by activated T-cells and mediates immunosuppression. The PD-1 ligands, PD-L1 (B7-H1) and PD-L2 (B7-DC), are expressed by tumor and stroma cells $(8,28-30)$. Therefore, $P D-1$ may also act as a molecular target for tumor progression in cancers. In vitro, the inhibition of the interaction between PD-1 and PD-L1 enhanced T-cell responses and mediated preclinical 
antitumor activity $(10,11)$. The use of an anti-PD-1 antibody has been initiated in advances for solid tumors in a study (31). The recent studies by Brahmer et al (14) and Topalian et al (13) have reported the safety and activity of anti-PD-L1 or PD-1 immunotherapy in cancers, including NSCLC. For NSCLC, $10 \%$ of patients responded to the anti-PD-L1 antibody (14) and $18 \%$ responded to the anti-PD-1 antibody (13). Notably, in the study by Topalain et al (13), the expression of PD-L1 correlated with the response. The majority of large retrospective studies showed that PD-1 expression was associated with a poor prognosis and/or more aggressive disease; however, numerous studies have indicated that there is an inadequate association $(16,32,33)$. This may be due to the heterogeneity in the expression within tumor tissue, the requirement to assess membrane PD-1 protein expression rather than intracellular protein or mRNA, the limited specificity of commercially available antibodies and the significant problems associated with developing methods for the detection of PD-1 expression in formalin-fixed, paraffin-embedded tissue. PD-1 contains only two small linear hydrophilic regions.

A previous study has shown that $-606 \mathrm{G} / \mathrm{A} P D-1$ is associated with rheumatoid arthritis in the Chinese population (34), but this SNP is rare in Europeans (1\%) and Africans (4\%) (34). Ishizaki et al (15) demonstrated that a haplotype with the $-606 \mathrm{G}$ allele and a high promoter activity was associated with the development of Japanese SSPE (15). The haplotype frequency of $P D-1$ containing the $-606 \mathrm{G}$ allele was significantly higher in SSPE patients compared to controls in the Japanese population. The promoter activity was significantly higher in the $-606 \mathrm{G}$ construct compared to the $-606 \mathrm{~A}$ allele. PD-1 expression levels were significantly higher in SSPE patients compared to the controls. The role of rs34819629 in intron 2 is not well known. However, $89.7 \%$ linkage disequilibrium with rs36084323 may indicate the genetic correlation of these SNPs.

In the analysis of the present study, the $P D-1$ SNP statuses correlated with the SCC prognosis, but not adeno. SCC exhibits a highly consistent immune profile, regarding the expression of such molecules as p63/cytokeratin 5/6/34bE-12 and non-expression of thyroid transcription factor-1. However, a higher heterogeneity is shown for these and other immune elements in adeno patients (35). Several analyses have identified that squamous tumors more frequently express tumor antigens, including melanoma-associated antigen or NY-ESO-1, compared with non-squamous tumors $(36,37)$. Thus, it is hypothesized that the possibility of establishing the patient selection for $P D-1$ SNPs on $P D-1$ expression in tumors requires prospective assessment. In addition, the development and validation of strategies to effectively improve the identification of the high-responder patient population with anti-PD-1 strategies are significant and likely to assume a place in the clinical practice.

In conclusion, PD-1 may promote the tumor prognosis of NSCLC, particularly in the early stage SCC patient population, and provide a candidate for blockade of its function as a strategy to antagonize the progression process.

\section{Acknowledgements}

The authors thank Miss Yuka Toda and Ito Yamamoto for their excellent technical assistances. The present study was supported by Grants-in-Aid for Scientific Research, Japan Society for the Promotion of Science (JSPS) (grant nos. 25293303, 24592097 and 23659674) and the Health and Labour Sciences Research Grant on Intractable Diseases (Neuroimmunological Diseases) from the Ministry of Health, Labour and Welfare of Japan.

\section{References}

1. Ginsberg RJ, Kris MK and Armstrong G (eds): Cancer of the lung. In: Principles and Practice of Oncology. 4th edition. Lippincott, Philadelphia, pp673-682, 1993.

2. Amano J, Kuwano $\mathrm{H}$ and Yokomise $\mathrm{H}$ : Thoracic and cardiovascular surgery in Japan during 2011: Annual report by The Japanese Association for Thoracic Surgery. Gen Thorac Cardiovasc Surg 61: 578-607, 2013.

3. Postmus PE: Chemotherapy for non-small cell lung cancer: the experience of the Lung Cancer Cooperative Group of the European Organization for Research and Treatment of Cancer. Chest 113 (Suppl 1): 28S-31S, 1998.

4. Zielinski C, Knapp S, Mascaux C and Hirsch F: Rationale for targeting the immune system through checkpoint molecule blockade in the treatment of non-small-cell lung cancer. Ann Oncol 24: 1170-1179, 2013.

5. Hanahan D and Weinberg RA: Hallmarks of cancer: the next generation. Cell 144: 646-674, 2011.

6. Zou W: Immunosuppressive networks in the tumour environment and their therapeutic relevance. Nature Rev Cancer 5: 263-274, 2005.

7. Chen L, Linsley PS and Hellström KE: Costimulation of T cells for tumor immunity. Immunol Today 14: 483-486, 1993.

8. Boise LH, Noel PJ and Thompson CB: CD28 and apoptosis. Curr Opin Immunol 7: 620-625, 1995

9. Watts TH and DeBenedette MA: T cell co-stimulatory molecules other than CD28. Curr Opin Immunol 11: 286-293, 1999.

10. Dong H, Strome SE, Salomao DR, et al: Tumor-associated B7-H1 promotes T-cell apoptosis: a potential mechanism of immune evasion. Nat Med 8: 793-800, 2002.

11. Iwai Y, Ishida M, Tanaka Y, et al: Involvement of PD-L1 on tumor cells in the escape from host immune system and tumor immunotherapy by PD-L1 blockade. Proc Natl Acad Sci USA 99: 12293-12297, 2002.

12. Zou W and Chen L: Inhibitory B7-family molecules in the tumour microenvironment. Nat Rev Immunol 8: 467-477, 2008.

13. Topalian SL, Hodi FS, Brahmer JR, et al: Safety, activity, and immune correlates of anti-PD-1 antibody in cancer. N Engl J Med 366: 2443-2454, 2012.

14. Brahmer JR, Tykodi SS, Chow LQ, et al: Safety and activity of anti-PD-L1 antibody in patients with advanced cancer. N Engl J Med 366: 2455-2465, 2012.

15. Ishizaki Y, Yukaya N, Kusuhara K, et al: PD1 as a common candidate susceptibility gene of subacute sclerosing panencephalitis. Hum Genet 127: 411-419, 2010.

16. Konishi J, Yamazaki K, Azuma M, et al: B7-H1 expression on non-small cell lung cancer cells and its relationship with tumor-infiltrating lymphocytes and their PD-1 expression. Clin Cancer Res 10: 5094-5100, 2004.

17. Sasaki H, Suzuki A, Shitara M, et al: PD-L1 gene expression in Japanese lung cancer patients. Biomed Rep 1: 93-96, 2013.

18. Sjöblom T, Jones S, Wood LD, et al: The consensus coding sequences of human breast and colorectal cancers. Science 314: 268-274, 2006.

19. Topalian SL, Weiner GJ and Pardoll DM: Cancer immunotherapy comes of age. J Clin Oncol 29: 4828-4836, 2011.

20. Mellman I, Coukos G and Dranoff G: Cancer immunotherapy comes of age. Nature 480: 480-489, 2011.

21. Drake CG, Jaffee E and Pardoll DM: Mechanisms of immune evasion by tumors. Adv Immunol 90: 51-81, 2006.

22. Mizoguchi H, O'Shea JJ, Longo DL, et al: Alterations in signal transduction molecules in T lymphocytes from tumor-bearing mice. Science 258: 1795-1798, 1992.

23. Hodi FS, O'Day SJ, McDermott DF, et al: Improved survival with ipilimumab in patients with metastatic melanoma. N Engl J Med 363: 711-723, 2010.

24. Robert C, Thomas L, Bondarenko I, et al: Ipilimumab plus dacarbazine for previously untreated metastatic melanoma. N Engl J Med 364: 2517-2526, 2011. 
25. Fife BT and Bluestone JA: Control of peripheral T-cell torelance and autoimmunity via the CTLA-4 and PD-1 pathways. Immunol Rev 224: 166-182, 2008.

26. Zhang Y,Zhang J, Deng Y, et al: Polymorphisms in the cytotoxic T-lymphocyte antigen 4 gene and cancer risk: a meta-analysis Cancer 117: 4312-4324, 2011.

27. Song B, Liu Y, Liu J, et al: CTLA- $4+49 \mathrm{~A}>\mathrm{G}$ polymorphism is associated with advanced non-small cell lung cancer prognosis. Respiration 82: 439-444, 2011.

28. Dong H, Zhu G, Tamada K and Chen L: B7-H1, a third member of the B7 family, co-stimulates T-cell proliferation and interleukin-10 secretion. Nat Med 5: 1365-1369, 1999.

29. Freeman GJ, Long AJ, Iwai Y, et al: Engagement of the PD-1 immunoinhibitory receptor by a novel B7 family member leads to negative regulation of lymphocyte activation. J Exp Med 192: 1027-1034, 2000.

30. Topalian SL, Drake CG and Pardoll DM: Targeting the PD-1/B7-H1 (PD-L1) pathway to activate anti-tumor immunity. Curr Opin Immunol 24: 207-212, 2012.
31. Brahmer JR, Drake CG, Wollner I, et al: Phase I study of single-agent anti-programmed death-1 (MDX-1106) in refractory solid tumors: safety, clinical activity, pharmacodynamics, and immunologic correlates. J Clin Oncol 28: 3167-3175, 2010.

32. Karim R, Jordanova ES, Piersma SJ, et al: Tumor-expressed B7-H1 and B7-DC in relation to PD-1+ T-cell infiltration and survival of patients with cervical carcinoma. Clin Cancer Res 15: 6341-6347, 2009

33. Sznol M and Chen L: Antagonist antibodies to PD-1 and B7-H1 (PD-L1) in the treatment of advanced human cancer. Clin Cancer Res 19: 1021-1034, 2013.

34. Kong EK, Prokunina-Olsson L, Wong WH, et al: A new haplotype of PDCD1 is associated with rheumatoid arthritis in Hong Kong Chinese. Arthritis Rheum 52: 1058-1062, 2005.

35. Rekhtman N, Ang DC, Sima CS, et al: Immunohistochemical algorithm for differentiation of lung adenocarcinoma and squamous cell carcinoma based on large series of whole-tissue sections with validation in small specimens. Mod Pathol 24: 1348-1359, 2011. 